\title{
Strong southward and northward currents observed in the inner plasma sheet
}

\author{
Yan-Yan Yang ${ }^{1,2}$, Chao Shen ${ }^{3}$, and Yong $\mathrm{Ji}^{4}$ \\ ${ }^{1}$ Institute of Crustal Dynamics, China Earthquake Administration, Beijing, 100085, China \\ ${ }^{2}$ Center for Satellite Application in Earthquake Science, China Earthquake Administration, Beijing, 100085, China \\ ${ }^{3}$ Harbin Institute of Technology, Shenzhen, 518055, China \\ ${ }^{4}$ Department of Mechanics and Engineering Science, Peking University, Beijing, 100871, China
}

Correspondence: Chao Shen (shenchao@hit.edu.cn)

Received: 11 April 2019 - Discussion started: 15 April 2019

Revised: 2 August 2019 - Accepted: 9 September 2019 - Published: 10 October 2019

\begin{abstract}
It is generally believed that field-aligned currents (FACs) and the ring current (RC) are two dominant parts of the inner magnetosphere. However, using the Cluster spacecraft crossing the pre-midnight inner plasma sheet in the latitudinal region between 10 and $30^{\circ} \mathrm{N}$, it is found that, during intense geomagnetic storms, in addition to FACs and the RC, strong southward and northward currents also exist which should not be FACs because the magnetic field in these regions is mainly along the $x-y$ plane. Detailed investigation shows that both magnetic-field lines (MFLs) and currents in these regions are highly dynamic. When the curvature of MFLs changes direction in the $x-y$ plane, the current also alternatively switches between being southward and northward. To investigate the generation mechanism of the southward and northward current, we employed the analysis of energetic particle flux up to $1 \mathrm{MeV}$. For energetic particles below $40 \mathrm{keV}$, observations from Cluster CIS/CODIF (Cluster Ion Spectrometry COmposition and DIstribution Function analyzer) are used. However, for higher-energy particles, the flux is obtained by extrapolations of low-energy particle data through Kappa distribution. The result indicates that the most reasonable cause of these southward and northward currents is the curvature drift of energetic particles.
\end{abstract}

\section{Introduction}

Abundant current systems existing in the Earth's magnetosphere play a very important role in energy transformation in different regions (Kuijpers et al., 2014). Recently, through simulations and observations, numerous studies have shown that the inner-magnetosphere currents have a more complicated structure and distribution than originally thought. For example, in the low latitude, the magnetic-field geometry can be altered significantly into a tail-like shape during storm time (Tsyganenko et al., 2003). One or multiple banana currents can exist in the inner magnetosphere, which makes the link of the current systems more complicated (Liemohn et al., 2013). In the high latitudes, field-aligned currents (FACs) have more sophisticated structures except for the known large-scale region-1 and region-2 currents (Mishin et al., 1997; Dunlop et al., 2015a, b). Therefore, more work is still needed to reveal the true nature of these current systems.

The huge progress in satellite deployments makes it possible for direct observation of the inner-magnetosphere current system. It is believed that the magnetosphere and ionosphere are linked through a ring current (RC) and FACs (e.g., Le et al., 2004; Zhang et al., 2011). Therefore, many investigations are mainly focused on these two current systems, from high (e.g., Iijima and Potemra, 1976, 1978; Wang et al., 2006; Dunlop et al., 2015a) to low latitudes (e.g., Vallat et al., 2005; Shen et al., 2014; Yang et al., 2016). The region from low to middle latitudes, which is the key area for the inner-magnetosphere current link, however, has received less attention. Graphic plots and some statistical results (e.g., Le et al., 2004) show that FACs should be the dominant current in these areas. Through Cluster satellite observations, Vallat et al. (2005) pointed out that the RC could exist at middle (or even high) latitudes. Despite the results achieved by these various research efforts, there are still no findings 
enabling a conclusion about the complete current morphology in low and middle latitudes. For example, are FACs and the RC the only currents in these regions? If there are other currents, what is the corresponding generation mechanism for them? To address these questions, the current distribution and magnetic-field geometry during two storm events are investigated in the latitudinal regions from 10 to $30^{\circ} \mathrm{N}$.

In the following, we will use Cluster fluxgate magnetometer (FGM; Balogh et al., 1997) data to conduct the analysis for two reasons: (1) the polar orbit of Cluster offers an opportunity to go through both the low-latitude and middle-latitude regions and (2) the configuration of the four Cluster satellites makes it possible to calculate the current via MaxwellAmpère's law and obtain the magnetic-field geometry. Moreover, in many previous works, it was thought that an asymmetric RC linked with the FACs, which is generally believed to occur during storm time, so storm events are our primary focus here.

Throughout this paper, solar magnetospheric (SM) coordinates are used. To better describe angles, spherical coordinates $(\theta, \varphi)$ in the SM frame are also defined; i.e., the polar angle $\theta\left(0^{\circ} \leq \theta \leq 180^{\circ}\right)$ is the angle between the $+z$ axis and the vector direction while the azimuthal angle $\varphi\left(0^{\circ} \leq \varphi \leq\right.$ $360^{\circ}$ ) is rotated anticlockwise from the $+x$ axis in the $x-y$ plane when seen from $+z$ axis. For current density analysis, the local cylindrical coordinate system $\left(j_{\rho}, j_{\varphi}, j_{z}\right.$; Vallat et al., 2005) is also utilized. Where $j_{z}$ is parallel to the $+z$ axis, $j_{\rho}$ represents the radial component of the current on the plane parallel to the $x-y$ plane, oriented anti-earthward; $j_{\varphi}$ points eastward, describing the RC.

\section{Methodology}

In this study, magnetic curvature analysis (MCA; Shen et al., 2003) and magnetic rotation analysis (MRA; Shen et al., 2007) are used; these techniques have the unique ability to reveal the three-dimensional geometric structure of the magnetic field directly as well as to provide more detailed magnetic-field-related parameters, such as the magnetic-field gradient; curvature; and the binormal of magnetic-field lines (MFLs), rotation rates, and current density. The magnetic unit vector $\hat{\boldsymbol{b}}=\boldsymbol{B} /|\boldsymbol{B}|$, curvature vector $\boldsymbol{\rho}_{\mathrm{c}}\left(\boldsymbol{\rho}_{\mathrm{c}}=(\hat{\boldsymbol{b}} \cdot \nabla) \hat{\boldsymbol{b}}\right)$, and the binormal vector $\hat{\boldsymbol{N}}\left(\hat{\boldsymbol{N}}=\hat{\boldsymbol{b}} \times \hat{\boldsymbol{\rho}}_{\mathrm{c}} /\left|\hat{\boldsymbol{b}} \times \hat{\boldsymbol{\rho}}_{\mathrm{c}}\right|\right)$ are orthogonal to each other in the analysis, and the radius of curvature is $R_{\mathrm{c}}=1 / \rho_{\mathrm{c}}$. The magnetic vector $\boldsymbol{b}$ has maximum, median, and minimum rotation rates of $\mu_{1}^{1 / 2}, \mu_{2}^{1 / 2}$, and $\mu_{3}^{1 / 2}$ along $\hat{\boldsymbol{e}}^{(1)}, \hat{\boldsymbol{e}}^{(1)}$, and $\hat{\boldsymbol{e}}^{(2)}$, respectively, where $\hat{\boldsymbol{e}}^{(1)}, \hat{\boldsymbol{e}}^{(1)}$, and $\hat{\boldsymbol{e}}^{(2)}$ are the three characteristic eigenvectors of the magnetic field. Note that because the strong geomagnetic field in the region of interest will produce artificial currents in the basic MRA calculation (nonlinear contributions), the dipole field is subtracted when using the MRA method to minimize truncation error (Shen et al., 2014).
To make a comparison with the nondisturbed geomagnetic field, the local dipolar values of the magnetic-field strength, $\boldsymbol{B}_{\mathrm{tDip}}$; the radius of curvature, $R_{\mathrm{cDip}}$; the magnetic-field gradient strength, $\left|\nabla \boldsymbol{B}_{\text {Dip }}\right|$; and three rotation rates, $\mu_{1}^{1 / 2}, \mu_{2}^{1 / 2}$, and $\mu_{3}^{1 / 2}$, are also presented. They are calculated (Shen et al., 2014) by using

$$
\begin{aligned}
\boldsymbol{B}_{\mathrm{tDip}} & =M r^{-3} \sqrt{\left(1+3 \cos ^{2} \theta\right)}, \\
R_{\mathrm{cDip}} & =\frac{r}{3} \sqrt{\left(1+3 \cos ^{2} \theta\right)^{3}} /\left[|\sin \theta| \cdot\left(1+\cos ^{2} \theta\right)\right], \\
\left|\nabla \boldsymbol{B}_{\text {Dip }}\right| & =3 M r^{-4} \\
& \cdot \sqrt{1+\cos ^{2} \theta\left(7+8 \cos ^{2} \theta\right)} / \sqrt{\left(1+3 \cos ^{2} \theta\right),} \\
\mu_{1}^{1 / 2} & =\mu_{\theta}^{1 / 2}=3\left(1+\cos ^{2} \theta\right) /\left[r\left(1+3 \cos ^{2} \theta\right)\right], \\
\mu_{2}^{1 / 2} & =\mu_{\phi}^{1 / 2}=3|\cos \theta| /\left[r \sqrt{\left(1+3 \cos ^{2} \theta\right)}\right], \\
\mu_{3}^{1 / 2} & =\mu_{r}^{1 / 2}=0,
\end{aligned}
$$

where $M=m \cdot \mu_{0} / 4 \pi$ (with $m=7.78 \times 10^{22} \mathrm{Am}^{-2}$ being the Earth's magnetic dipole moment) and $r$ is the radial distance in SM coordinates.

\section{Event analysis}

The chosen events occurred on 12 April 2001 and 31 March 2001. These were the two largest storms from 2001 to 2004 during which the four Cluster satellites had a small (best) tetrahedron separation distance $(\leq 1000 \mathrm{~km})$. The minimum Dst indices for the two events were -271 and $-387 \mathrm{nT}$, respectively. During the two events, Cluster was in the pre-midnight sector and traversed the RC region vertically from the Southern to Northern Hemispheres. The region of interest is in the Northern Hemisphere. Figure 1 gives the proton density and differential flux for $\mathrm{H}^{+}, \mathrm{He}^{+}$, and $\mathrm{O}^{+}$ during the analyzed interval, which are obtained from the Cluster Ion Spectrometer (CIS; Rème et al., 2001). The figure indicates that Cluster is mainly in the plasma sheet region (e.g., Vallat et al., 2005).

\subsection{April 2001 event}

The time interval of interest for the first event is from 05:00 to $05: 25 \mathrm{UT}$, with latitude ranging from 16.9 to $25.7^{\circ}$. Figure 2 presents some of the main physical quantities. Figure $2 \mathrm{a}$ shows the average magnetic field $\left\langle\boldsymbol{B}_{\mathrm{t}}\right\rangle$ detected from the four Cluster satellites and the local dipolar magnetic-field strength. It can be seen that the local magnetic field is enhanced in this area. Figure $2 b$ indicates that the polar angle of the magnetic field is close to $90^{\circ}$, showing that the magnetic field lies approximately in the $x-y$ plane. The polar angle and azimuthal angle of dipolar fields are also shown in dashed lines in Fig. 2b, which indicates a large deviation of the polar angle with observations. Figure $2 \mathrm{c}$ shows that the radius of curvature, $R_{\mathrm{c}}$, has large variations. It is interesting 

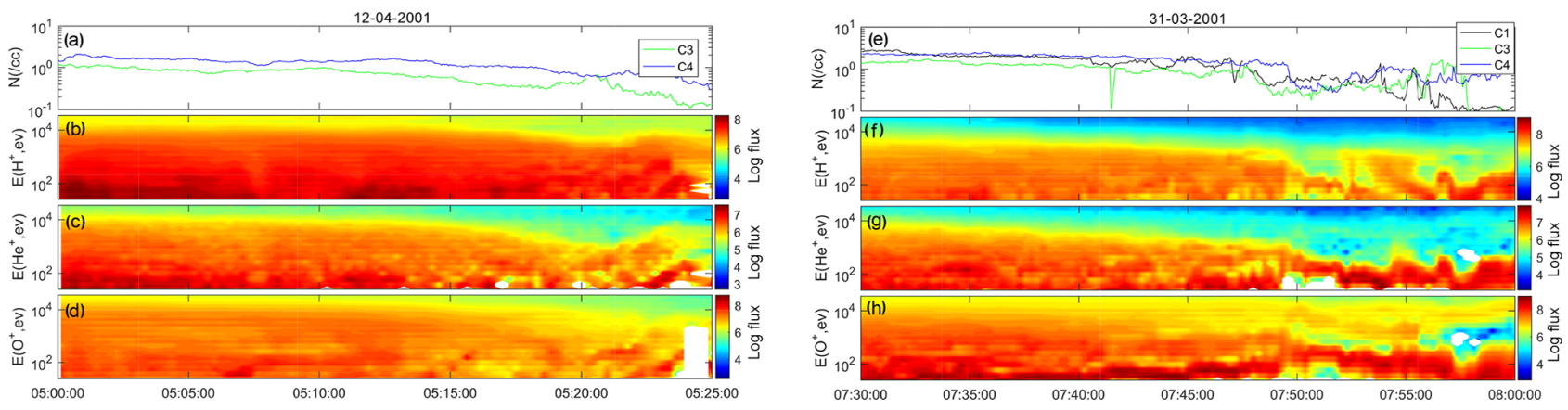

Figure 1. Cluster CIS data for 12 April 2001 (left) and 31 March 2001 (right) event. (a, e) The proton density variation for three satellites: C1 (black), C3 (green), and C4 (blue). (b-d, f-h) $\mathrm{H}^{+}, \mathrm{He}^{+}$, and $\mathrm{O}^{+}$energy-time spectrograms in particle flux units (ions $\mathrm{cm}^{-2} \mathrm{sr}^{-1} \mathrm{~s}^{-1} \mathrm{keV}^{-1}$ ) from $\mathrm{C} 4$.

to see that $\phi_{\mathrm{c}}$ (the angle of $R_{\mathrm{c}}$ in Fig. 2d) changes direction alternately during the whole period. Therefore, eight regions (numbered from $\mathrm{NH} 1$ to NH8) were chosen according to the changes in the $\phi_{\mathrm{c}}$ direction to investigate their features. The variations in some physical quantities are also summarized in Table 1. For $\phi_{\mathrm{c}}$ and $\theta_{\mathrm{e} 1}$, the average values (with a few large abnormal points removed) during this period are given. The "_" denotes values with large oscillations. For $j_{z}$, the maximum or minimum value during each interval is presented.

As shown in Fig. 2c, the radius of curvature of MFLs in the eight regions is more varied compared with that of the dipole field. Another feature observed in Fig. $2 \mathrm{c}$ is that $R_{\mathrm{c}}$ peaks at the vertical dashed lines. This is reasonable, since the curvature radius in the transition region should be larger than the region where the curvature radius has opposite directions. Figure $2 \mathrm{~d}$ and the $\phi_{\mathrm{c}}$ row in Table 1 give the average value of the azimuthal direction $\phi_{\mathrm{c}}$ during each interval. This quantitatively reveals that $\phi_{\mathrm{c}}$ alternatively varied between 30.3 and 51.9 and 230.3 and $292.0^{\circ}$. It is noted from Fig. $2 \mathrm{~d}$ that, for some regions, the variation in polar angle $\theta_{\mathrm{c}}$ has larger fluctuation (than azimuthal angle $\phi_{\mathrm{c}}$ ). This feature reflects larger changes of the magnetic field in $z$ component. Figure $2 \mathrm{~g}$ shows that $\mu_{1}^{1 / 2}$ has an enhancement in each region, illustrating a stretched MFL structure. Figure $2 \mathrm{~h}$ and row $\theta_{e}$ in Table 1 show that, for most regions, the largest value of the polar angle $\theta_{e 1}$ for $\mu_{1}^{1 / 2}$ is close to $90^{\circ}$; therefore, the largest deviation of MFLs is along the $x-y$ plane. Figure $2 \mathrm{i}$ indicates that the current oscillates and that the dominant current is along $j_{\rho}$ and the north (or south) $j_{z}$ direction, while $j_{\varphi}$ is basically small compared with $j_{\rho}$ and $j_{z}$. To show FACs, the $j_{B}$ component is also given in Fig. 2i; it can be seen that the value of $j_{B}$ is close to that of $j_{\rho}$ because the direction of the magnetic field points approximately to the radial direction (see Fig. 2b). The maximum values for $j_{B}$ and $j_{z}$ were $\sim 40$ and $\sim 80 \mathrm{nAm}^{-2}$, respectively. From Table 1 and Fig. 2 , it is interesting to see that, from region $\mathrm{NH} 1$ to region $\mathrm{NH} 8$, the $j_{z}$ component changed from positive (northward) to negative (southward) as $\phi_{\mathrm{c}}$ varied from $<50$ to $>230^{\circ}$.

\subsection{March 2001 event}

Another larger storm occurred between 07:30 and 08:00 UT on 31 March 2001. The event was once reported by Shen et al. (2014), but they only concentrated on the interval from approximately 07:00 to 07:25 UT. Observations are shown in Fig. 3 for the latitudinal region from 13.1 to $31.2^{\circ} \mathrm{N}$, the interval during the main phase of the storm. Here, 11 regions designated from $\mathrm{NH} 1$ to $\mathrm{NH} 11$ are divided also according to azimuthal direction changes of $\phi_{\mathrm{c}}$. The variations in some relative physical quantities are also shown in Table 1. From Fig. 3 and Table 1, it can be seen that these parameters behave the same as those of the first event, but with strong magnetic-field strength. Figure 3 indicates that the magneticfield strength is stronger than that during the first event. The magnetic field is in the $x-y$ plane (see Fig. 3b). The radius of curvature of MFLs (see Fig. 3c), the magnetic-field gradient (Fig. 3e), and the largest rotation rate (Fig. 3g) oscillates significantly and exhibits large deviations compared with those of the dipole field. Figure $3 \mathrm{f}$ shows that the magnetic-field gradient is in the $x-y$ plane and directed toward the dayside. Figure $3 \mathrm{~h}$ and row $\theta_{e 1}$ demonstrate that the largest variation in MFLs is near the $x-y$ plane. In Fig. $3 \mathrm{i}$, it is clear that the $j_{z}$ component is the dominant current, with a maximum value of $\sim 300 \mathrm{nAm}^{-2}$. This value is more than triple that of the 12 April 2001 event. It is clear to see that the $j_{\varphi}$ component is the smallest among these currents. Similar to first event, $j_{z}$ is simultaneously observed to vary from northward to southward when $\varphi_{\mathrm{c}}$ changes direction.

\section{Discussion}

During the 12 April 2001 and 31 March 2001 strong storm events, the Cluster satellites were located in the pre-midnight sector and crossed from $\sim 10$ to $\sim 30^{\circ} \mathrm{N}$. In these regions, both the magnetic-field parameters and the current density fluctuated significantly. The MFLs, which were mainly in the $x-y$ plane, severely deviated from the dipole field and changed (stretched) along the $x-y$ plane. Figure 4 displays 


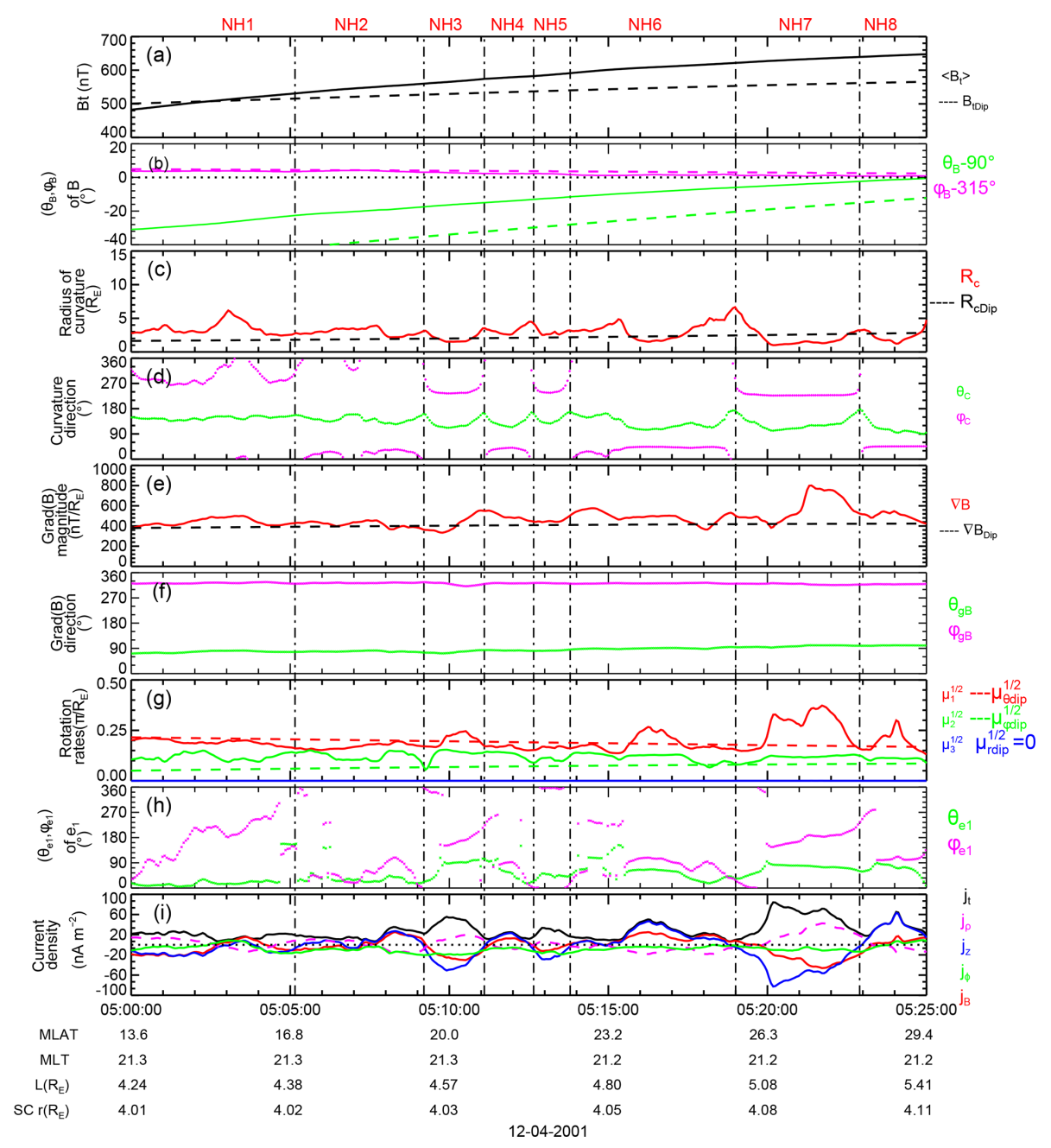

Figure 2. Geometry of the magnetic field and the current distribution in the Northern Hemisphere (NH) region on 12 April 2001. (a) Average magnetic strength $B_{\mathrm{t}}$ at the center of the Cluster tetrahedron (black solid line) and the calculated strength $\boldsymbol{B}_{\mathrm{tDip}}$ of the dipole geomagnetic field (black dashed line). (b) Direction angles $\left(\theta_{B}, \phi_{B}\right)$ of the magnetic field. 90 and $315^{\circ}$ are reduced respectively for $\theta_{B}$ and $\phi_{B}$ to better indicate the magnetic-field variation. The polar angle and azimuthal angle of dipolar fields are also show in dashed lines. (c) Radius of curvature, $R_{\mathrm{c}}$ (red solid line), and the calculated radius of curvature, $R_{\mathrm{cDip}}$, of the dipole geomagnetic field (black dashed line). (d) Direction angles $\left(\theta_{\mathrm{c}}, \phi_{\mathrm{c}}\right)$ of the curvature of the MFLs. (e) Value of the gradient of magnetic-field strength for the real magnetic field (red solid line) and dipole geomagnetic field (black dashed line). (f) Direction angles $\left(\theta_{\mathrm{g} B}, \phi_{\mathrm{g} B}\right)$ of the gradient of magnetic-field strength. (g) Maximum, median, and minimum rotation rates of the measured magnetic field (solid lines) and dipole geomagnetic field (dashed lines). (h) Direction angles $\left(\theta_{e 1}, \phi_{e 1}\right)$ of the maximum rotation rate. (i) Total current density $j_{\mathrm{t}}$ (black line) and the three components $j_{\rho}$ (magenta line), $j_{\varphi}$ (green line), and $j_{z}$ (blue line) in local cylindrical coordinate system, respectively. The red line is the field-aligned component $j_{B}$ (red line).

the total magnetic-field strength and its three components. It can be seen that the $x$ and $y$ components of the magnetic field have the largest fluctuations, which is consistent with the results obtained from Figs. 2 and 3. To further investigate the fluctuation, the continuous 1-D wavelet transform method is applied in the $x$ and $y$ component of the magnetic field. It is found that the ULF wave (ultra-low-frequency wave) covering a range of frequencies spanning from 4 to $10 \mathrm{mHz}$ can be observed (not shown here), which is consistent with the typical current density variation in the $\sim 2-4$ min period. Actually, the ULF wave in the plasma sheet region has been ex- tensively reported in previous works (see Keiling, 2009, and references therein). Thus, it seems that ULF wave is a possible way to cause the variation in the curvature radius (and the field-aligned current).

The most obvious phenomenon in the two cases is the existence of three current systems, i.e., FACs, $j_{B}$, an azimuthal current, $j_{\varphi}$, and a northward (or southward) current, $j_{z}$. Among them, $j_{z}$ is basically the strongest current component. In previous studies (e.g., Le et al., 2004; Vallat et al., 2005), the existence of $j_{B}$ and $j_{\varphi}$ has been proved. However, the occurrence of such a strong $j_{z}$ in the inner plasma 
Table 1. Variation in physical quantities for two storm events.

\begin{tabular}{|c|c|c|c|c|c|c|c|c|c|c|c|c|}
\hline Event $^{\mathrm{a}}$ & $\mathrm{PQ}^{\mathrm{b}}$ & $\mathrm{NH} 1^{\mathrm{c}}$ & $\mathrm{NH} 2^{\mathrm{d}}$ & $\mathrm{NH} 3^{\mathrm{e}}$ & $\mathrm{NH} 4^{\mathrm{f}}$ & $\mathrm{NH}_{5} \mathrm{~g}$ & $\mathrm{NH}^{\mathrm{h}}$ & $\mathrm{NH}^{\mathrm{i}}$ & $\mathrm{NH} 8^{\mathrm{j}}$ & $\mathrm{NH} 9^{\mathrm{k}}$ & $\mathrm{NH} 10^{\mathrm{l}}$ & $\mathrm{NH}_{11}{ }^{\mathrm{m}}$ \\
\hline \multirow{3}{*}{12 Apr 2001} & $\phi_{\mathrm{c}}\left({ }^{\circ}\right)$ & 292.0 & 41.4 & 244.1 & 35.3 & 251.9 & 36.9 & 230.3 & 44.8 & & & \\
\hline & $\theta_{e 1}\left(^{\circ}\right)$ & 29.5 & 27.0 & 74.7 & 57.7 & 51.9 & 61.0 & 70.8 & 69.7 & & & \\
\hline & $j_{z \mathrm{~m}}\left(\mathrm{nA} \mathrm{m}^{-2}\right)$ & -22.5 & 27.2 & -50.8 & 23.3 & -28.8 & 46.6 & -82.6 & 63.1 & & & \\
\hline \multirow{3}{*}{31 Mar 2001} & $\phi_{\mathrm{c}}\left({ }^{\circ}\right)$ & 59.9 & 241.9 & 59.6 & 244.7 & 58.5 & 240.3 & 63.2 & 235.1 & 60.5 & 238.6 & 62.8 \\
\hline & $\theta_{e 1}\left({ }^{\circ}\right)$ & 71.3 & - & 65.4 & 73.2 & 71.8 & 59.8 & 73.4 & 71.7 & 78.8 & 59.9 & 80.2 \\
\hline & $j_{z \mathrm{~m}}\left(\mathrm{nAm}^{-2}\right)$ & 106.9 & -42.5 & 60.1 & -128.3 & 95.9 & -126.3 & 198.2 & -294.3 & 118.2 & -193.9 & 204.7 \\
\hline
\end{tabular}

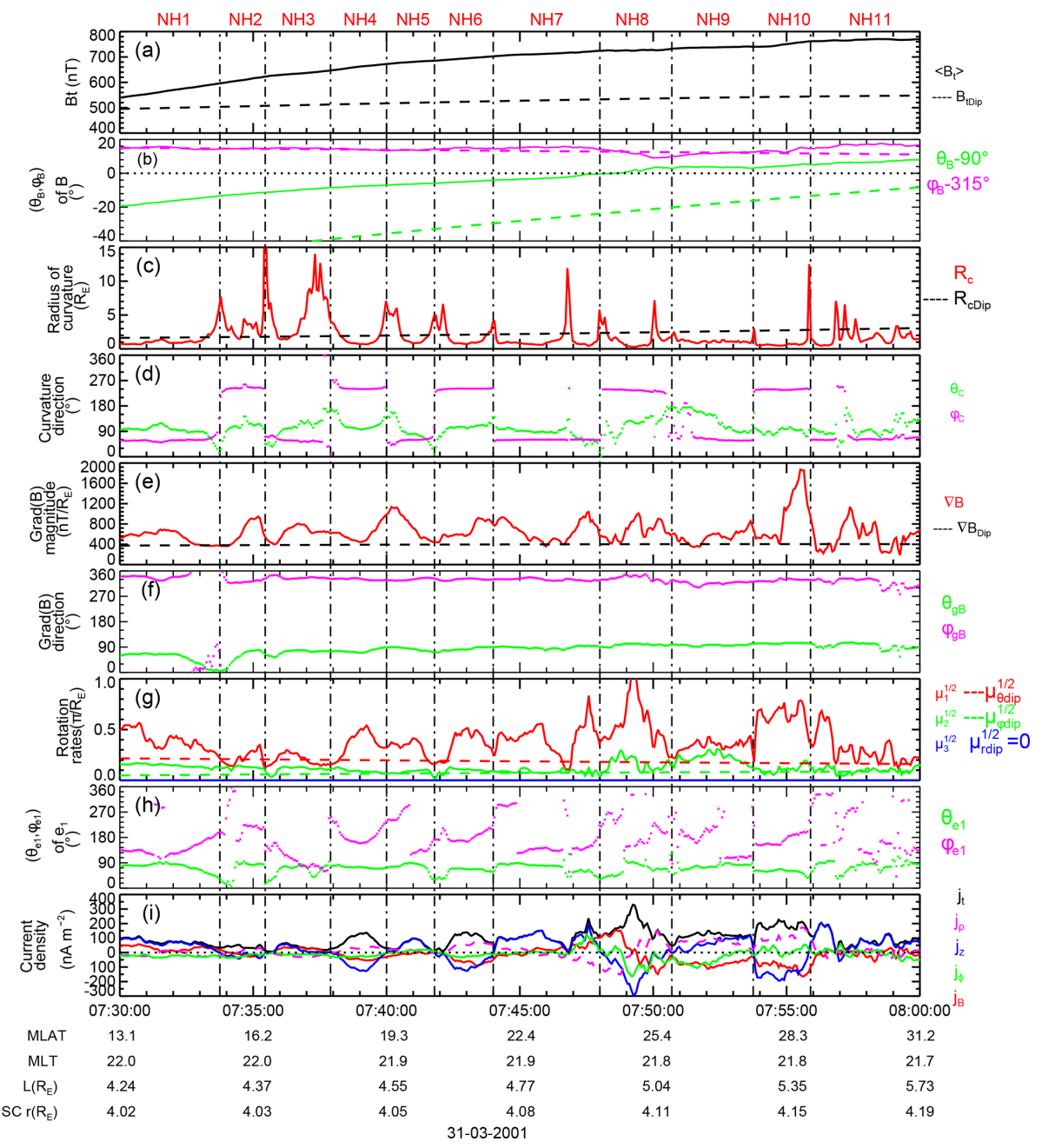

Figure 3. Geometry of the magnetic field and the current distribution in the NH region on 31 March 2001. The format is the same as that of Fig. 2.

sheet has not been reported before. In the work of Vallat et al. (2005), they also found a southward current (see Fig. 14 and corresponding text). But it is in the equatorial ring current region (with no direction changes) and is mainly caused by an asymmetry between the ionospheric conductivities of the two hemispheres. It is very clear that the southward current in their paper is different than what we report here.

As introduced in previous studies (e.g., Parker, 1957), the current in the inner magnetosphere generally arises from gradient drifts as well as curvature drift and the gyromotion of energetic particles. They can be calculated by using the fol- 

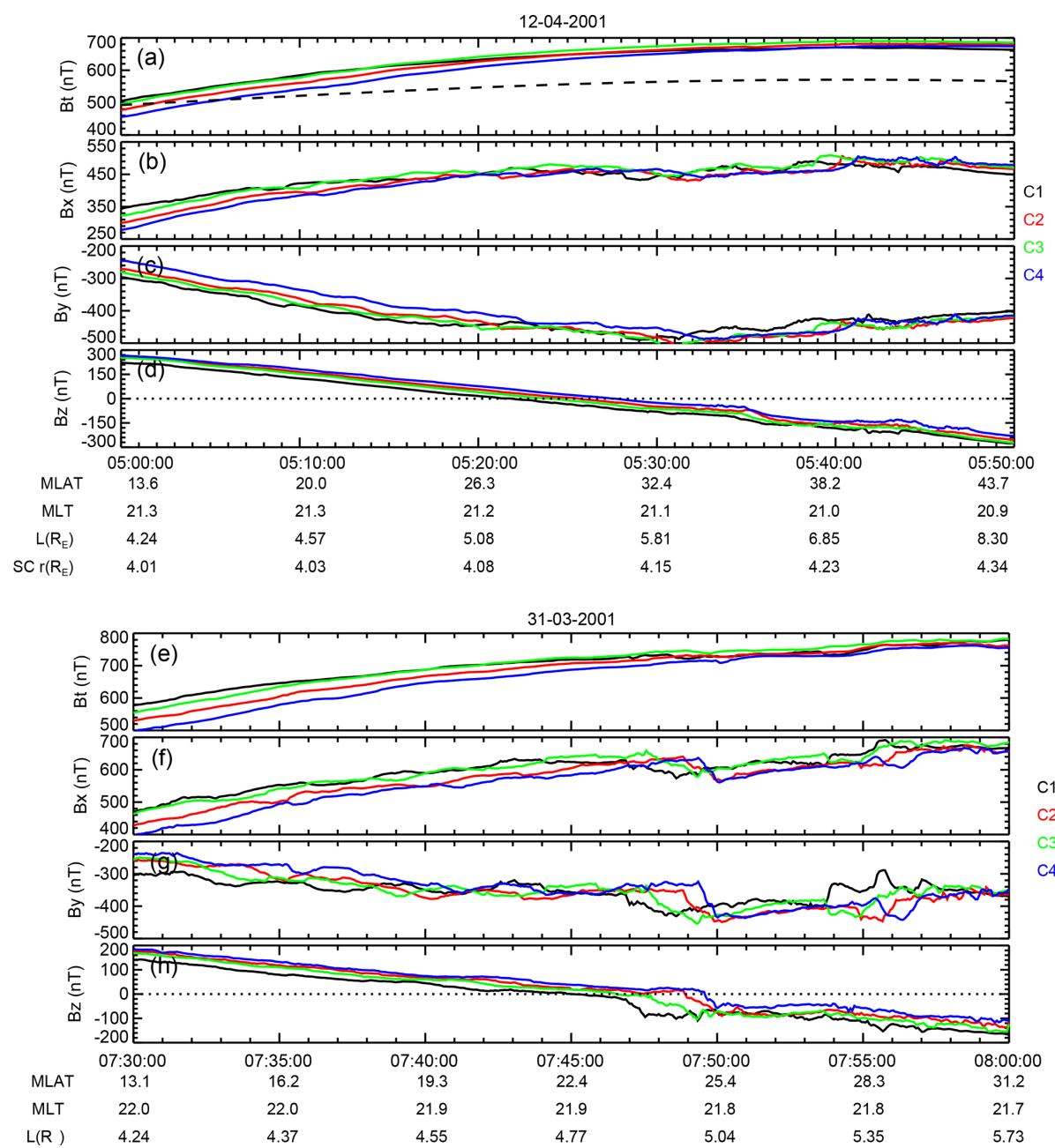

Figure 4. Magnetic field observed by the four Cluster satellites during 12 April 2001 and 31 March 2001 storm events.

lowing (e.g., Lui et al., 1987; De Michelis et al., 1999):

$\boldsymbol{j}_{\nabla}=P_{\perp} \frac{\boldsymbol{B} \times \nabla \boldsymbol{B}}{B^{3}}$,

$j_{\mathrm{C}}=-\frac{P_{\|}}{B^{2}} \rho_{\mathrm{c}} \times \boldsymbol{B}$,

$\boldsymbol{j}_{\mathrm{G}}=\frac{\boldsymbol{B}}{B^{2}} \times\left[\nabla P_{\perp}-\frac{P_{\perp}}{\boldsymbol{B}} \nabla \boldsymbol{B}-\frac{P_{\perp}}{B^{2}}(\boldsymbol{B} \cdot \nabla) \boldsymbol{B}\right]$,

where $\boldsymbol{j}_{\nabla}, \boldsymbol{j}_{\mathrm{C}}$, and $\boldsymbol{j}_{\mathrm{G}}$ represent the gradient current, curvature current, and gyromotion current, respectively, and $P_{\perp}$ and $P_{\|}$are the pressure tensor components perpendicular and parallel to the magnetic field, which can be deduced from

$P_{\perp}=\pi \sqrt{2 m} \iint J \sqrt{\varepsilon} \sin ^{3} \alpha \mathrm{d} \alpha \mathrm{d} \varepsilon$

$P_{\|}=2 \pi \sqrt{2 m} \iint J \sqrt{\varepsilon} \cos ^{2} \alpha \sin \alpha \mathrm{d} \alpha \mathrm{d} \varepsilon$,

where $m$ is the mass of the particle, $J$ is the differential flux intensity, and $\varepsilon$ and $\alpha$ are the particle energy and pitch angle, respectively. Since the magnetic-field gradient $\nabla \boldsymbol{B}$ and curvature $\rho_{\mathrm{c}}$ were obtained by using the MRA method, the above three currents can be calculated when the pressure tensor components are given.

For the two events in this study, both the magnetic field and magnetic-field gradient are directed toward the dayside. Therefore, the current deduced from $\boldsymbol{B} \times \nabla \boldsymbol{B}$ (the gradient drift current) should be small. To analyze the current contribution from gyromotion drift and curvature drift, we first show the three components of $-\rho_{\mathrm{c}} \times \boldsymbol{B}$ for the two events in Fig. 5a and b. It is clearly seen that the $\left(-\rho_{\mathrm{c}} \times \boldsymbol{B}\right)_{z}$ component is the dominate part and has the same variation trend as $j_{z}$. Therefore, the curvature drift current is a possible candidate. For gyromotion current, it originates from three terms, i.e., $\boldsymbol{B} \times \nabla P_{\perp},-\boldsymbol{B} \times \nabla \boldsymbol{B}$, and $-\boldsymbol{B} \times(\boldsymbol{B} \cdot \nabla) \boldsymbol{B}$. Firstly, according to previous works (e.g., Lui et al., 1987; De Michelis et al., 1999), $\nabla P_{\perp}$ is along the radial direction, which means that it has a similar direction with the magnetic field to the two events analyzed here. Thus, the contribution from $\boldsymbol{B} \times \nabla P_{\perp}$ should be small. Secondly, $-\boldsymbol{B} \times \nabla \boldsymbol{B}$ is similar to the gradient drift current and can be negligible. 
Thirdly, since $(\boldsymbol{B} \cdot \nabla) \boldsymbol{B}$ has the same direction as $\boldsymbol{\rho}_{\mathrm{c}}\left(\boldsymbol{\rho}_{\mathrm{c}}=\right.$ $(\hat{\boldsymbol{b}} \cdot \nabla) \hat{\boldsymbol{b}}, \hat{\boldsymbol{b}}=\boldsymbol{B} /|\boldsymbol{B}|)$, according to Fig. $5 \mathrm{a}$ and b, the product of $-\boldsymbol{B} \times(\boldsymbol{B} \cdot \nabla) \boldsymbol{B}\left(\right.$ similar to $\left.\boldsymbol{\rho}_{\mathrm{c}} \times \boldsymbol{B}\right)$ will behave oppositely to $j_{z}$. Consequently, the gyromotion current has little possibility of contributing to a strong $j_{z}$. According to the above analysis, the most reasonable candidate for strong $j_{z}$ should be the curvature drift.

Based on the above analysis, graphic plots are given in Fig. $5 \mathrm{c}$ and $\mathrm{d}$ to explain the possible generation mechanism for $j_{z}$. During the strong storm time, turbulence, e.g., ULF waves, results in the fluctuation of the MFLs; then, the radius of curvature of the MFLs decreases, leading to an increase in the curvature drift current. During this process, the direction of the magnetic field is nearly unchanged because the background field is very strong. However, the curvature will alternately change directions along with the variation in the MFLs, resulting in alternating variations in $-\boldsymbol{\rho}_{\mathrm{c}} \times \boldsymbol{B}$, i.e., leading to the oscillation of $j_{z}$.

Figure $5 \mathrm{a}$ and $\mathrm{b}$ can only illustrate that the direction of $-\boldsymbol{\rho}_{\mathrm{c}} \times \boldsymbol{B}$ is consistent with northward current. To quantitatively check if the curvature current calculated through Eq. (3) is consistent with the result obtained from the MRA method, further investigation is necessary. The CIS/CODIF (Cluster Ion Spectrometry COmposition and DIstribution Function analyzer) can provide the differential flux intensity for energy below $40 \mathrm{keV}$. Through Eqs. (3), (5), and (6), the curvature current can be estimated. The results show that the main variation trend is consistent with result from MRA, but the intensity is very small (less than $1 \mathrm{nAm}^{-2}$; not shown here). However, it should be noted that, for Cluster CIS/CODIF, only low-energy particle data are available; therefore, a large bias may exist when calculating the stormtime current. In contrast, much higher energy is used in previous studies (e.g., $1 \mathrm{MeV}$ in the work of Lui et al., 1987). Cluster RAPID can provide energy spectrograms for the highenergy particle from $\sim 27.6$ to $\sim 3056 \mathrm{keV}$. Unfortunately, there are no available data for the two analyzed events. The statistical study from Kronberg et al. (2015) proves that, in the near-Earth plasma sheet, higher-energy hydrogen and oxygen are greatly enhanced during geomagnetic activity. In the work of Ma et al. (2012), they also indicated that the flux for higher-energy particles could be comparable or larger than that of the low-energy particles.

Though, there is no available differential flux for highenergy particles on Cluster, the curvature current still can be estimated through simulations. Previous works have proved that the particle distribution in plasma sheet can be described as Kappa distribution functions (Pierrard and Lazar, 2010, and references therein):

$$
f=N_{1}\left(\frac{1}{2 \pi m E_{0} \kappa_{1}}\right)^{2 / 3} \frac{\Gamma\left(\kappa_{1}+1\right)}{\Gamma\left(\kappa_{1}-1 / 2\right)}\left(1+\frac{E}{\kappa_{1} E_{0}}\right)^{-\kappa_{1}-1}
$$

where $N_{1}$ and $E_{0}$ denote particle density and temperature, and $\kappa_{1}$ is a constant. For energy satisfying $E \gg E_{0}$, Eq. (7) can be written as

$f=a E^{-\kappa_{1}-1}$.

Since the differential flux intensity $J$ and particle velocity distribution function $f$ are related by $J=f p^{2}$, Eq. (8) is also the function of $J$, namely

$J=a p^{2} E^{-\kappa_{1}-1}$,

where $p$ is the momentum of the concerned particles, and $a$ is a constant. Thus, with the known differential flux intensity from low-energy particle, the parameter $a$ and $\kappa_{1}$ can be determined. Then, the differential flux intensity for high-energy particles (to $1 \mathrm{MeV}$ ) can be estimated using Eq. (9). Though particles are accelerated during the storm, we have confirmed that the Kappa distribution is still satisfied using CIS/CODIF observations (not shown here). However, it should be noted that, during the storm, $a$ and $\kappa_{1}$ are no longer a constant but varied with time. Besides this, to check if the estimated high-energy particle differential flux (using low-energy particle data) is reasonable, we select a storm event that occurred on 20 April 2002, which has similar position with two analyzed events in this study, and has CIS/CODIF and RAPID observations at the same time. The result shows that the fitted result (from CIS/CODIF measurement) can basically reflect the main trend of the high-energy particles, which can demonstrate that our estimation used here is reasonable. During the storm time, currents calculated via energetic particle fluxes appear to still underestimate the current. As the particle flux fit method of calculating currents works so well for earlier in the time period, this undershoot during storm time might be indicative of additional energetic particle acceleration (a harder power law) in the parallel direction. This increased parallel pressure would result in the observed larger value of $j_{\mathrm{c}}$.

Now, we can re-estimate the curvature current using Cluster CIS/CODIF observations for energy between $25 \mathrm{eV}$ and $40 \mathrm{keV}$ and simulation values for energy in the range $>$ $40 \mathrm{keV}-1 \mathrm{MeV}$. Figure 6 shows the estimated $z$ component of curvature current (the red dotted curve). It is close to result from MRA (the blue curve).

It should be noted that both events analyzed here are in the Northern Hemisphere. Actually, we have checked that the southward and northward current also can be observed in the southern low and middle latitudes. Thus, such currents should be observable both in northern and southern inner plasma sheet during strong geomagnetic storm events.

According to previous analysis from plasma data (Baker et al., 2002; Korth et al., 2004; Vallat et al., 2005; Ohtani et al., 2007), most NH regions should correspond to the plasma sheet region. Using the T96 model (Tsyganenko, 1995, 1996), we tried to trace Cluster footprints in the Northern Hemisphere; it is found that the position is $\sim 55-60^{\circ}$ (not 

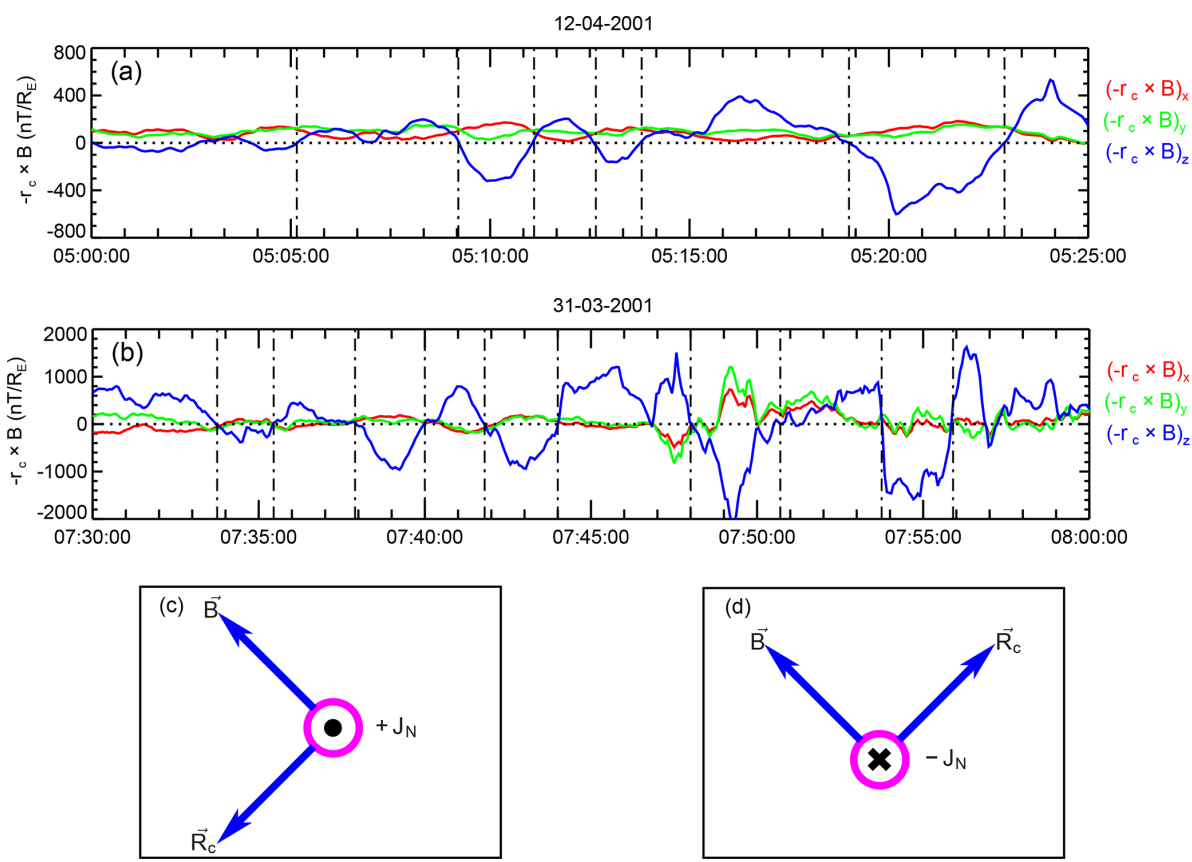

Figure 5. (a, b) The three components of $-\rho_{\mathrm{c}} \times \boldsymbol{B}$ for two analyzed events. $\boldsymbol{\rho}_{\mathrm{c}}$ is calculated from MRA method, and $\boldsymbol{B}$ is the averaged magnetic field measured by four Cluster spacecraft. $(\mathbf{c}, \mathbf{d})$ Graphic plots of the origin of the $j_{N}$ current variation.
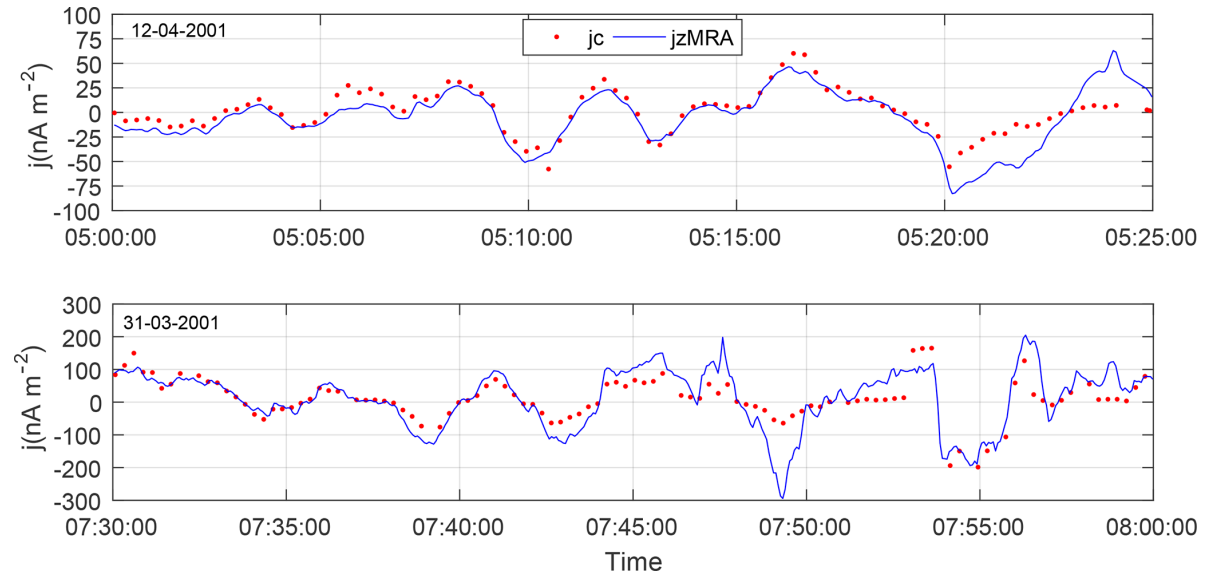

Figure 6. The z-component current density calculated from MRA method (the blue curve) and the estimated curvature current (the red dotted curve).

shown here), which just corresponds to the position of the FACs (Papitashvili et al., 2002; He et al., 2012). Because the MFL shapes in the plasma sheet were changed considerably, the particle motion in Earth's magnetic field will be altered correspondingly, which may affect the particle distribution in the polar and equatorial regions, hence leading to the variation in the FAC and RC distributions. These effects, however, need to be evaluated in future work.

When calculating current density using the MRA method, it should be noted that Cluster is not a regular tetrahedron shape around the perigee area but suffers from an elongation, which can produce an unnatural currents. These unnat- ural currents are included in our analysis and cannot be removed. To evaluate this component, methods from Robert et al. (1998) and Vallat et al. (2005) are used. Figure 7 gives the Cluster tetrahedron parameters for two analyzed events. Then, the current influence of the tetrahedron shape can be estimated as a function of elongation and planarity (Fig. 7c and d). It can be seen that the error caused by tetrahedron is never more than $30 \%$. 

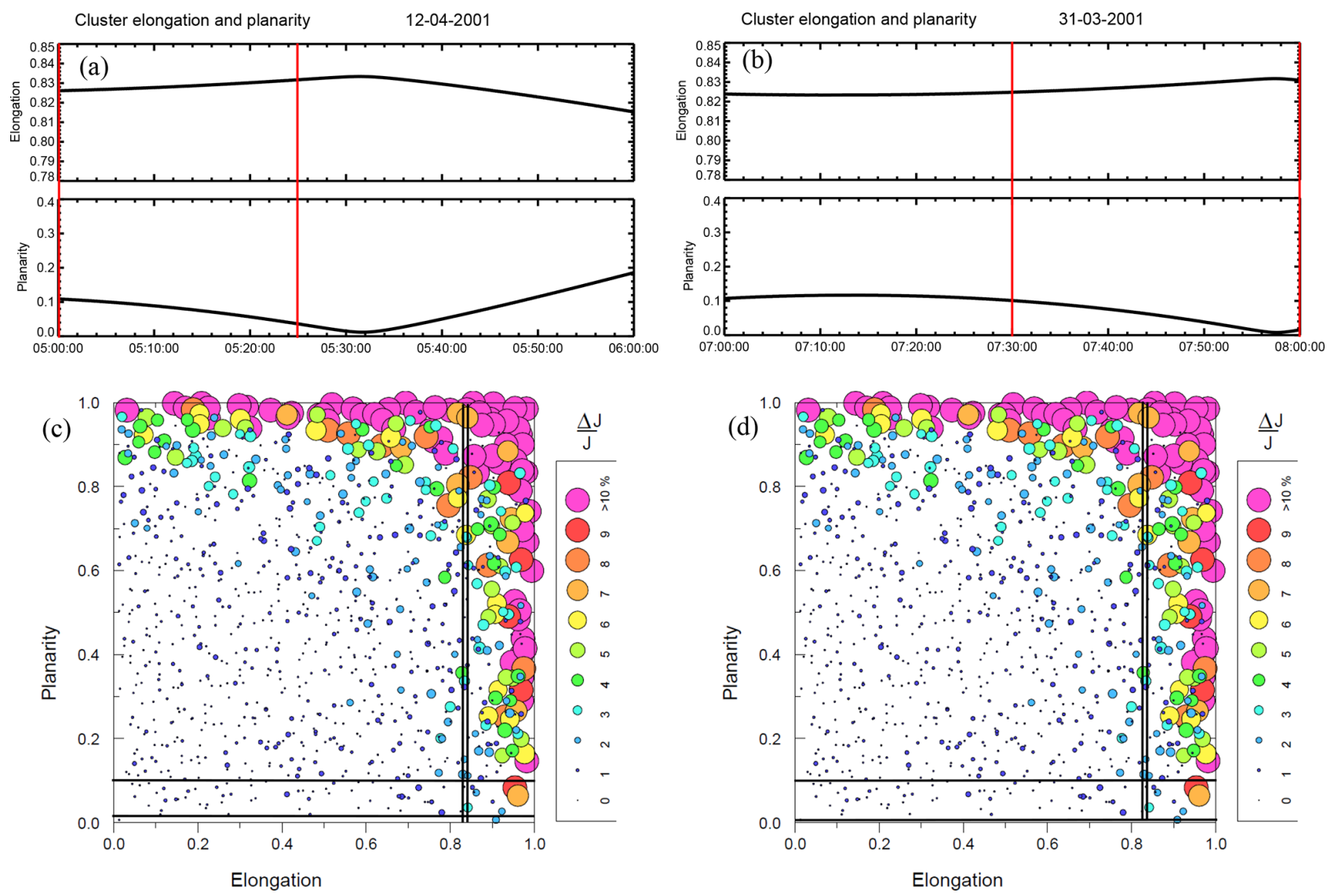

Figure 7. (a, b) Cluster elongation and planarity for two studied events. The red vertical lines demarcate the analyzed time interval. Panels (c) and (d) are taken from Robert et al. (1998) to evaluate the influence of the tetrahedron shape. Black lines mark the elongation and planarity obtained from panels (a) and (b).

\section{Summary}

In this work, the magnetic-field geometry and current density in the inner plasma sheet during two intense geomagnetic storms were investigated. It is found that the magnetic field and current density highly fluctuated in this region. Generally, all three components of current can be observed during the analyzed interval. However, the northward (or southward) current is basically the strongest one. Detailed study shows that the MFLs align in the $x-y$ plane; thus, the northward (or southward) current should not be FACs. This property has not been reported before.

The most prominent feature of the northward (or southward) current is the alternative changing of its direction, which is found to vary simultaneously with that of the curvature. To reveal the generation mechanism of the northward (or southward) current, gradient current, curvature current, and gyromotion current are analyzed. The results show that the curvature current has the same variation trend with the northward and southward current. Then, using low-energy particle observations from Cluster CIS/CODIF, combined with simulations based on Kappa distribution, the curvature current is calculated. It shows that the estimated curvature current coincides very well with the current density directly obtained from MCA and MRA. Therefore, the curvature drift of the energetic particle is the most reasonable mechanism of the southward and northward current.

For the two events analyzed in this work, we can observe ULF waves; this is consistent with the typical current density variation period. This turbulence excited during the strong storm can result in the decrease in curvature radius and changing of direction of MFLs, then leading to an increase in the curvature currents and variation in their direction.

Data availability. Solar wind data (OMNI data set) were obtained from http://omniweb.gsfc.nasa.gov (last access: 22 June 2019); Cluster FGM and CIS/CODIF data were obtained, respectively, from ftp://cdaweb.gsfc.nasa.gov/pub/data/Cluster/ (last access: 22 June 2019) and https://www.cosmos.esa.int/web/csa (last access: 22 June 2019). 
Author contributions. CS was responsible for the interpretation, YJ performed the simulation, and YYY performed the data analysis and prepared the paper.

Competing interests. The authors declare that they have no conflict of interest.

Acknowledgements. We are grateful to the Cluster Science Archive, CDAWeb and OMNI for providing us with data.

Financial support. This research has been supported by the National Key R\&D Program of China (grant no. 2018YFC1503501), the National Natural Science Foundation of China (grant no. 41231066), the National Natural Science Foundation of China (grant no. 41204117), and a research grant from the Institute of Crustal Dynamics, China Earthquake Administration (grant no. ZDJ2018-18).

Review statement. This paper was edited by Minna Palmroth and reviewed by two anonymous referees.

\section{References}

Baker D. N., Ergun, R. E., Burch, J. L., Jahn, J. M., Daly, P. W., Friedel, R., Reeves, G. D., Fritz, T. A., and Mitchell, D. G.: A telescopic and microscopic view of a magnetospheric substorm on 31 March 2001, Geophys. Res. Lett., 29, 1862, https://doi.org/10.1029/2001GL014491, 2002.

Balogh, A., Dunlop, M. W., Cowley, S. W. H., Southwood, D. J., Thomlinson, J. G., Glassmeier, K. H., Musmann, G., Luhr, H., Buchert, S., Acuna, M. H., Fairfield, D. H., Slavin, J. A., Riedler, W., Schwingenschuh, K., and Kivelson, M. G.: The Cluster magnetic field investigation, Space Sci. Rev., 79, 65-91, https://doi.org/10.1023/a:1004970907748, 1997.

De Michelis, P., Daglis, I. A., and Consolini, G.: An average image of proton plasma pressure and of current systems in the equatorial plane derived from AMPTE/CCECHEM measurements, J. Geophys. Res., 104, 28615-28624, https://doi.org/10.1029/1999JA900310, 1999.

Dunlop, M. W., Yang, Y. Y., Yang, J. Y., Lühr, H., Shen, C., Olsen, N., Ritter, P., Zhang, Q. H., Cao, J. B., Fu, H. S., and Haagmans, R.: Multispacecraft current estimates atswarm, J. Geophys. Res.-Space Phys., 120, 8307-8316, https://doi.org/10.1002/2015JA021707, 2015a.

Dunlop, M. W., Yang, J. Y., Yang, Y. Y., Xiong, C., Lühr, H., Bogdanova, Y. V., Shen, C., Olsen, N., Zhang, Q. H., Cao, J. B., Fu, H. S., Liu, W. L., Carr, C. M., Ritter, P., Masson, A., and Haagmans, R.: Simultaneous field-aligned currents at Swarm and Cluster satellites, Geophys. Res. Lett., 42, 36833691, https://doi.org/10.1002/2015GL063738, 2015 b.

He, M., Vogt, J., Lühr, H., Sorbalo, E., Blagau, A., Le, G., and Lu, G.: A high-resolution model of field-aligned currents through empirical orthogonal functions analysis (MFACE), Geophys.
Res. Lett., 39, L18105, https://doi.org/10.1029/2012GL053168, 2012.

Iijima, T. and Potemra, T. A.: Field-aligned currents in the dayside cusp observed by Triad, J. Geophys. Res., 81, 5971, https://doi.org/10.1029/JA081i034p05971, 1976.

Iijima, T. and Potemra, T. A.: Large-scale characteristics of fieldaligned currents associated with substorms, J. Geophys. Res., 83, 599-615, https://doi.org/10.1029/JA083iA02p00599, 1978.

Keiling, A.: Alfvén waves and their roles in the dynamics of the Earth's magnetotail: A review, Space Sci. Rev., 142, 73-156, https://doi.org/10.1007/s11214-008-9463-8, 2009.

Korth, A., Fränz, M., Zong, Q. G., Fritz, T. A., Sauvaud, J. A., Rème, H., Dandouras, I., Friedel, R., Mouikis, C. G., Kistler, L. M., Möbius, E., Marcucci, M. F., Wilber, M., Parks, G., Keiling, A., Lundin, R., and Daly, P. W.: Ion injections at auroral latitude during the March 31, 2001 magnetic storm observed by Cluster, Geophys. Res. Lett., 31, L20806, https://doi.org/10.1029/2004GL020356, 2004.

Kronberg, E. A., Grigorenko, E. E., Haaland, S. E., Daly, P. W., Delcourt, D. C., Luo, H., Kistler, L. M., and Dandouras, I.: Distribution of energetic oxygen and hydrogen in the near-Earth plasma sheet, J. Geophys. Res.-Space Phys., 120, 3415-3431, https://doi.org/10.1002/2014JA020882, 2015.

Kuijpers, J., Frey, H., and Fletcher, L.: Electric Current Circuits in Astrophysics, Space Sci. Rev., 188, 1-55, 2014.

Le, G., Russell, C. T., and Takahashi, K.: Morphology of the ring current derived from magnetic field observations, Ann. Geophys., 22, 1267-1295, https://doi.org/10.5194/angeo-22-12672004, 2004.

Liemohn, M. W., Ganushkina, N. Y., Katus, R. M., De Zeeuw, D. L., and Welling, D. T.: The magnetospheric banana current, J. Geophys. Res.-Space Phys., 118, 1-13, https://doi.org/10.1002/jgra.50153, 2013.

Lui, A. T. Y., McEntire, R. W., and Krimigis, S. M.: Evolution of the ring current during two geomagnetic storms, J. Geophys. Res., 92, 7459-7470, https://doi.org/10.1029/JA092iA07p07459, 1987.

Ma, Y., Shen, C., Angelopoulos, V., Lui, A. T. Y., Li, X., Frey, H. U., Dunlop, M., Auster, H. U., McFadden, J. P., and Larson, D.: Tailward leap of multiple expansions of the plasma sheet during a moderately intense substorm: THEMIS observations, J. Geophys. Res., 117, A07219, https://doi.org/10.1029/2012JA017768, 2012.

Mishin, V. M., Block, L. P., Bazarzhapov, A. D., Saifudinova, T. I., Lunvushkin, S. B., Shirapov, D. S., Woch, J., Eliasson, L., Marklund, G. T., Biotaberg, L. G., and Opgenoor, H.: A study of the CDAW 9C substorm of May 3, 1986, using magnetograrn inversion technique 2 , and a substorm scenario with two active phases, J. Geophys. Res., 102, 19845-19859, https://doi.org/10.1029/97JA00154, 1997.

Ohtani, S., Korth, H., Brandt, P. C., Blomberg, L. G., Singer, H. J., Henderson, M. G., Lucek, E. A., Frey, H. U., Zong, Q., Weygand, J. M., Zheng, Y., and Lui, A. T. Y.: Cluster observations in the inner magnetosphere during the 18 April 2002 sawtooth event: Dipolarization and injection at $r=4.6 R_{\mathrm{E}}$, J. Geophys. Res., 112, A08213, https://doi.org/10.1029/2007JA012357, 2007.

Papitashvili, V. O., Christiansen, F., and Neubert, T.: A new model of field-aligned currents derived from high-precision 
satellite magnetic field data, Geophys. Res. Lett., 29, 1683, https://doi.org/10.1029/2001GL014207, 2002.

Parker, E. N.: Newtonian development of the dynamical properties of ionized gases of low density, Phys. Rev., 107, 924-933, 1957.

Pierrard, V. and Lazar, M.: Kappa distributions: Theory and applications in space plasmas, Solar Phys., 267, 153-174, https://doi.org/10.1007/s11207-010-9640-2, 2010.

Rème, H., Aoustin, C., Bosqued, J. M., Dandouras, I., Lavraud, B., Sauvaud, J. A., Barthe, A., Bouyssou, J., Camus, Th., Coeur-Joly, O., Cros, A., Cuvilo, J., Ducay, F., Garbarowitz, Y., Medale, J. L., Penou, E., Perrier, H., Romefort, D., Rouzaud, J., Vallat, C., Alcaydé, D., Jacquey, C., Mazelle, C., d'Uston, C., Möbius, E., Kistler, L. M., Crocker, K., Granoff, M., Mouikis, C., Popecki, M., Vosbury, M., Klecker, B., Hovestadt, D., Kucharek, H., Kuenneth, E., Paschmann, G., Scholer, M., Sckopke, N., Seidenschwang, E., Carlson, C. W., Curtis, D. W., Ingraham, C., Lin, R. P., McFadden, J. P., Parks, G. K., Phan, T., Formisano, V., Amata, E., Bavassano-Cattaneo, M. B., Baldetti, P., Bruno, R., Chionchio, G., Di Lellis, A., Marcucci, M. F., Pallocchia, G., Korth, A., Daly, P. W., Graeve, B., Rosenbauer, H., Vasyliunas, V., McCarthy, M., Wilber, M., Eliasson, L., Lundin, R., Olsen, S., Shelley, E. G., Fuselier, S., Ghielmetti, A. G., Lennartsson, W., Escoubet, C. P., Balsiger, H., Friedel, R., Cao, J.-B., Kovrazhkin, R. A., Papamastorakis, I., Pellat, R., Scudder, J., and Sonnerup, B.: First multispacecraft ion measurements in and near the Earth's magnetosphere with the identical Cluster ion spectrometry (CIS) experiment, Ann. Geophys., 19, 1303-1354, https://doi.org/10.5194/angeo-19-1303-2001, 2001.

Robert, P., Dunlop, M. W., Roux, A., and Chanteur, G.: Accuracy of current density determination, in Analysis Methods for MultiSpacecraft data, ISSI Sci. Rep., SR-001, 395-418, 1998.

Shen, C., Li, X., Dunlop, M., Liu, Z. X., Balogh, A., Baker, D. N., Hapgood, M., and Wang, X.: Analyses on the geometrical structure of magnetic field in the current sheet based on cluster measurements, J. Geophys. Res., 108, 1168, https://doi.org/10.1029/2002JA009612, 2003.

Shen, C., Li, X., Dunlop, M., Shi, Q. Q., Liu, Z. X., Lucek, E., and Chen, Z. Q.: Magnetic field rotation analysis and the applications, J. Geophys. Res., 112, A06211, https://doi.org/10.1029/2005JA011584, 2007.
Shen, C., Yang, Y. Y., Rong, Z. J., Li. X., Dunlop, M., Carr, C. M., Liu, Z. X., Baker, D. N., Chen, Z. Q., Ji, Y., and Zeng, G.: Direct calculation of the Ring Current distribution and magnetic structure seen by Cluster during Geomagnetic Storms, J. Geophys. Res.-Space Phys., 119, 2458-2465, https://doi.org/10.1002/2013JA019460, 2014.

Tsyganenko, N. A.: Modeling the Earth's magnetospheric magnetic field, confined within a realistic magnetopause, J. Geophys. Res., 100, 5599-5612, 1995.

Tsyganenko, N. A.: Effects of the solar wind conditions on the global magnetospheric configuration as deduced from data-based field models, in: Proceedings of the Third International Conference on Substorms (ICS-3), Versailles, France, 12-17 May 1996, edited by: Rolfe, E. and Kaldeich, B., Eur. Space Agency Spec. Publ., ESA-SP, 389, 181-185, 1996.

Tsyganenko, N. A., Singer, H. J., and Kasper, J. C.: Storm-time distortion of the inner magnetosphere: How severe can it get?, J. Geophys. Res., 108, 1209, https://doi.org/10.1029/2002JA009808, 2003.

Vallat, C., Dandouras, I., Dunlop, M., Balogh, A., Lucek, E., Parks, G. K., Wilber, M., Roelof, E. C., Chanteur, G., and Rème, H.: First current density measurements in the ring current region using simultaneous multi-spacecraft CLUSTER-FGM data, Ann. Geophys., 23, 1849-1865, https://doi.org/10.5194/angeo23-1849-2005, 2005.

Wang, H., Lühr, H., Ma, S. Y., Weygand, J., Skoug, R. M., and Yin, F.: Field-aligned currents observed by CHAMP during the intense 2003 geomagnetic storm events, Ann. Geophys., 24, $311-$ 324, https://doi.org/10.5194/angeo-24-311-2006, 2006.

Yang, Y. Y., Shen, C., Dunlop, M., Rong, Z. J., Li, X., Angelopoulos, V., Chen, Z. Q., Yan, G. Q., and Ji, Y.: Storm time current distribution in the inner equatorial magnetosphere: THEMIS observations, J. Geophys. Res.-Space Phys., 121, 5250-5259, https://doi.org/10.1002/2015JA022145, 2016.

Zhang, Q.-H., Dunlop, M. W., Lockwood, M., Holme, R., Kamide, Y., Baumjohann, W., Liu, R.-Y., Yang, H.-G., Woodfield, E. E., Hu, H.-Q., Zhang, B.-C., and Liu, S.-L.: The distribution of the ring current: Cluster observations, Ann. Geophys., 29, 16551662, https://doi.org/10.5194/angeo-29-1655-2011, 2011. 